\title{
THERMAL IMAGING MEASUREMENT AND CORRELATION OF THERMAL DIFFUSIVITY IN CONTINUOUS FIBER CERAMIC COMPOSITES $^{\dagger}$
}

\author{
J. G. Sun, C. Deemer, W. A. Ellingson, T. E. Easler,* A. Szweda,* \\ and P. A. Craig** \\ Energy Technology Division \\ Argonne National Laboratory \\ Argonne, IL 60439 \\ *Dow Corning Corp. \\ Midland, MI 48686 \\ **DuPont Lanxide Composites Inc. \\ RECEIVED \\ OCT 241997 \\ OSTI \\ Newark, DE 19714
}

September 1997

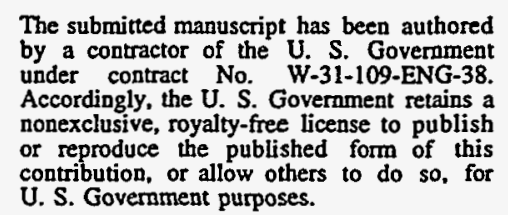

Paper of presentation at 24th International Thermal Conductivity Conference, Pittsburgh, PA, October 26-29, 1997.

${ }^{\dagger}$ Research sponsored jointly by Dow Corning and the U.S. Department of Energy, Energy Efficiency and Renewable Energy, Office of Industrial Technologies, under Contract W-31-109-ENG-88 and Cooperative Agreement Nos. DE-FC02-92CE40993 and DE-FC02-92CE40999. 


\section{DISCLAIMER}

This report was prepared as an account of work sponsored by an agency of the United States Government. Neither the United States Government nor any agency thereof, nor any of their employees, makes any warranty, express or implied, or assumes any legal liability or responsibility for the accuracy, completeness, or usefulness of any information, apparatus, product, or process disclosed, or represents that its use would not infringe privately owned rights. Reference herein to any specific commercial product, process, or service by trade name, trademark, manufacturer, or otherwise does not necessarily constitute or imply its endorsement, recommendation, or favoring by the United States Government or any agency thereof. The views and opinions of authors expressed herein do not necessarily state or reflect those of the United States Government or any agency thereof. 


\section{DISCLAIVIER}

Portions of this document may be illegible in electronic image products. Images are produced from the best available original document. 


\title{
THERMAL IMAGING MEASUREMENT AND CORRELATION OF THERMAL DIFFUSIVITY IN CONTINUOUS FIBER CERAMIC COMPOSITES
}

\author{
J. G. Sun, C. Deemer, W. A. Ellingson, T. E. Easler,* A. Szweda,* and P. A. Craig** \\ Energy Technology Division \\ Argonne National Laboratory \\ Argonne, II 60439 \\ *Dow Corning Corp. \\ Midland, MI 48686 \\ **DuPont Lanxide Composites Inc. \\ Newark, DE 19714
}

\begin{abstract}
Continuous fiber ceramic matrix composites (CFCCs) are currently being developed for a variety of high-temperature applications, including use in advanced heat engines. For such composites, knowledge of porosity distribution and presence of defects is important for optimizing mechanical and thermal behavior of the components. The assessment of porosity and its distribution is also necessary during composite processing to ensure component uniformity. To determine the thermal properties of CFCC materials, and particularly for detecting defects and nonuniformities, we have developed an infrared thermal imaging method to provide a "single-shot" full-field measurement of thermal diffusivity distributions in large components. This method requires that the back surface of a specimen receives a thermal pulse of short duration and that the temperature of the front surface is monitored as a function of time. The system has been used to measure thermal diffusivities of several CFCC materials with known porosity or density values, including SYLRAMIC ${ }^{\mathrm{TM}} \mathrm{SiC} / \mathrm{SiNC}$ composite samples from Dow Corning and SiC/SiC and enhanced $\mathrm{SiC} / \mathrm{SiC}$ samples from DuPont Lanxide Composites, to determine the relationship of thermal diffusivity to component porosity or density.
\end{abstract}

\section{INTRODUCTION}

Continuous fiber ceramic composites (CFCCs) are currently being developed for a variety of high-temperature applications, including use in advanced heat engines, due to their relatively high strength and toughness at high temperatures and their relatively low density. In the

- development of CFCC materials, quantification of their mechanical and thermal properties is necessary. Furthermore, flaws and defects that may result in subsequent failure of the part must be detected before the part goes into service. To meet this need, we developed a system that uses infrared thermal imaging to provide full-field through-thickness measurement of thermal diffusivity distributions in a component (Stuckey, et al., 1997). The theoretical model used in this system is based on a one-dimensional conductive heat transfer solution proposed by Parker et al. (1961).

The thermal imaging system was used to measure thermal diffusivities of several CFCC materials with known porosity or density values, including SYLRAMIC ${ }^{\mathrm{TM}} \mathrm{SiC} / \mathrm{SiNC}$ composite samples from Dow Corning and $\mathrm{SiC} / \mathrm{SiC}$ and enhanced $\mathrm{SiC} / \mathrm{SiC}$ samples from DuPont Lanxide Composites. The measurement results show the general linear relationship between the thermal diffusivity and component density for these materials and provide information on the uniformity and completeness of the material processing. 


\section{THERMAL DIFFUSIVITY MEASUREMENT SYSTEM}

To measure thermal diffusivity based on the Parker et al. (1961) method, the front surface of a sample is heated instantaneously. Heat conduction through the sample, which is related to thermal diffusivity of the material, is determined by measuring the speed of temperature rise at the back surface. Figure 1 shows the theoretically predicted back-surface temperature $\mathrm{T}$ as a function of time $t$ and specimen thickness $L$ according to the relationship

$$
T(L, t)=\frac{Q}{\rho C L}\left[1+2 \sum_{n=1}^{\infty}(-1)^{n} \exp \left(-\frac{n^{2} \pi^{2}}{L^{2}} \alpha t\right)\right],
$$

where $Q$ is the radiant energy incident on the front surface at $t=0, \rho$ is density, $C$ is specific heat, and $\alpha$ is thermal diffusivity. Because the axes of Fig. 1 have been normalized (i.e., $V=T / T_{M}$ and $\omega=\alpha t \pi^{2} / L^{2}$, where $T_{M}$ is the maximum front-surface temperature), the relationship is universal to all specimens.

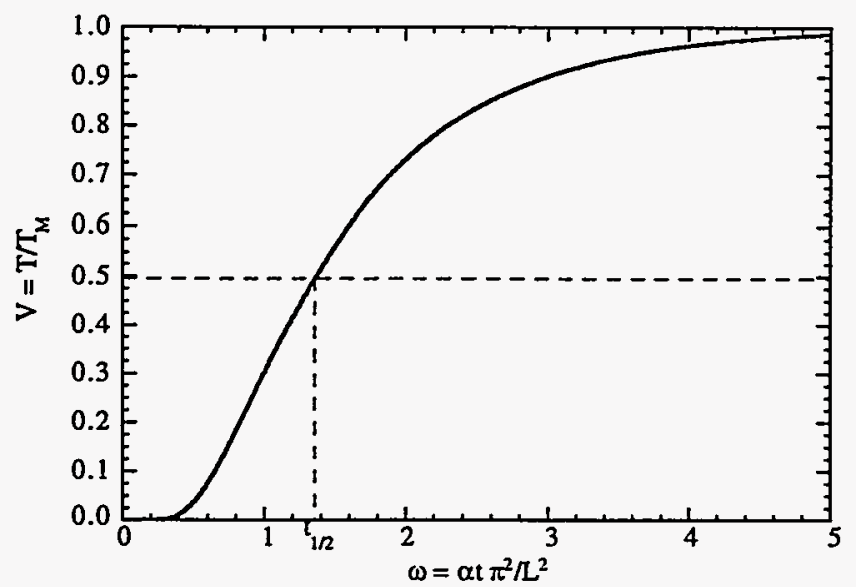

Fig. 1. Theoretical prediction of back-surface temperature rise.

One method to determine the thermal diffusivity is the "half-rise-time" $\left(t_{10}\right)$ method. When the back-surface temperature rise has reached half of its maximum, i.e., $V=0.5$, we have $\omega=$ 1.37. Thus, using the "half-rise-time" method,

$$
\alpha=\frac{1.37 L^{2}}{\pi^{2} t_{1 / 2}} .
$$

The experimental apparatus for the thermal imaging is illustrated in Fig. 2. The apparatus includes an IR camera consisting of a focal plane array of $256 \times 256 \mathrm{InSb}$ detectors, a $200 \mathrm{Mhz}$ Pentium-based PC computer equipped with a digital frame grabber with DSP processor, a flash lamp system for the thermal impulse, a function generator for camera operation, and a dual timing trigger circuit for camera and external trigger control. An analog video system is used to monitor the experiments. For a typical measurement of a $256 \times 256$ array of diffusivity image, processing time ranges from 8 to $20 \mathrm{~min}$, depending on the number of frames taken. 


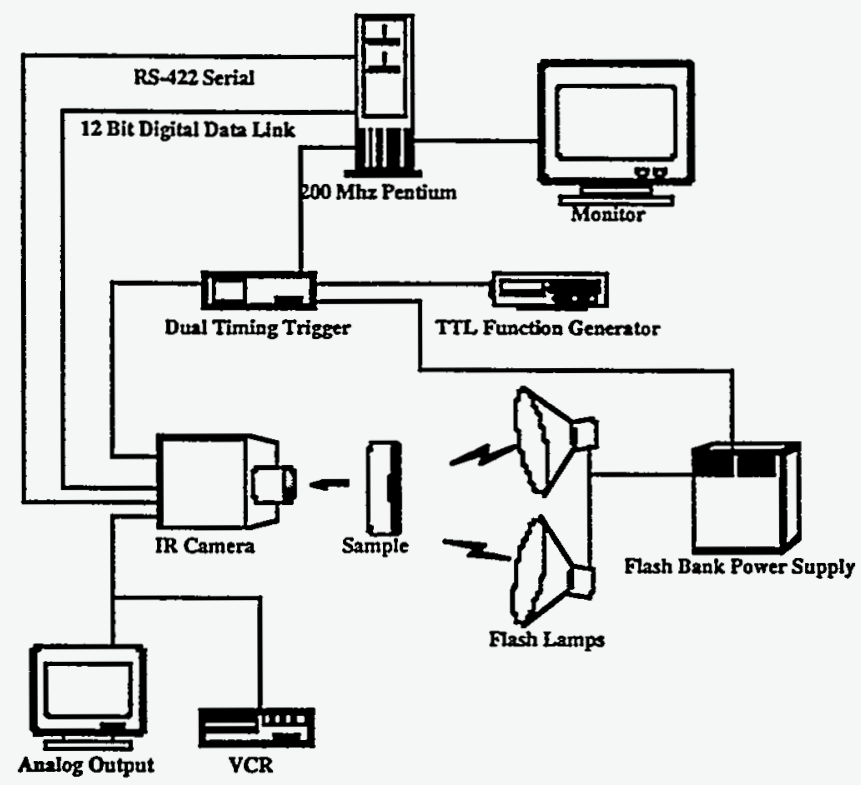

Fig 2. Experimental thermal imaging apparatus.

To check the accuracy of the thermal diffusivity measurement, a NIST standard graphite specimen was used. Its thermal diffusivity value was reported to be between 0.74 and $0.76 \mathrm{~cm}^{2} / \mathrm{s}$ (see Stuckey et al., 1997). The specimen is $25.4 \mathrm{~mm}$ (1 in.) in diameter and its mean thickness is $5.87 \mathrm{~mm}$. The sample was mounted in a sample holder whose edges were carefully insulated to prevent radiation leaking through. The camera was set to an operating rate of $330 \mathrm{~Hz}$. The resulting single pixel history with the theoretical curve is shown in Fig. 3. The mean diffusivity value was found to be $0.72 \mathrm{~cm}^{2} / \mathrm{s}$, with a standard deviation of $0.027 \mathrm{~cm}^{2} / \mathrm{s}$. This deviation was attributed to variations in specimen thickness (Stuckey et al., 1997).

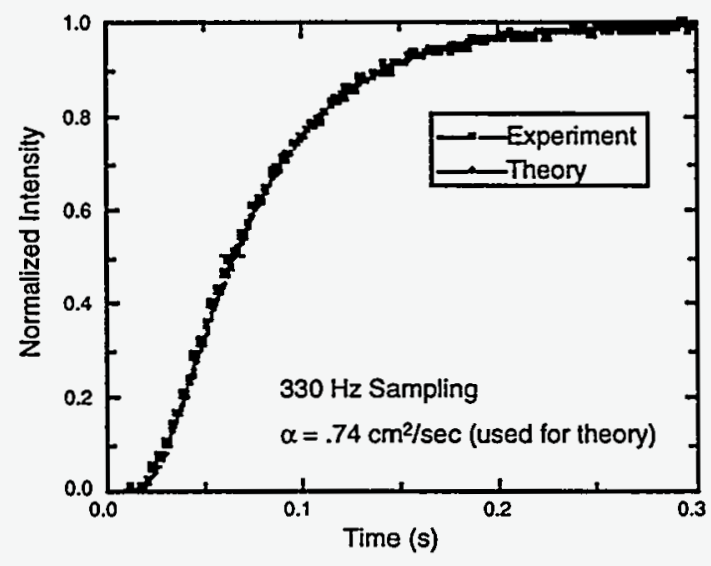

Fig. 3. Comparison of theoretical and experimental single-pixel history data.

\section{DOW CORNING SYLRAMIC ${ }^{\mathrm{TM}} \mathrm{SiC} / \mathrm{SINC}$ COMPOSITE SAMPLES}

SYLRAMIC ${ }^{\mathrm{TM}}$ composites are fabricated by a Polymer Impregnation and Pyrolysis (PIP) process developed by Dow Corning Corporation. The SYLRAMIC ${ }^{\text {TM }}$ composites for this study are reinforced with Nicalon ${ }^{\mathrm{TM}} \mathrm{SiC}$ fibers, which are small-diameter, textile-grade ceramic fibers. 
The matrix-precursor polymer is first impregnated into the fiber architecture of choice and then cured by conventional methods. Both the initial shaping and fabrication of the composite are carried out with low-temperature processing equipment. The composite is then pyrolyzed to temperatures greater than $1000^{\circ} \mathrm{C}$ to convert the pre-ceramic matrix polymer into a ceramic. Subsequent impregnation and pyrolysis cycles are used to achieve the desired final density or open porosity. Eight composite samples were prepared for this study, with processing that used 1, 3, 5 , $7,9,11,13$, and 15 PIP cycles.

Thermal imaging was conducted on these SYLRAMIC ${ }^{\mathrm{TM}}$ composite samples. Figure 4 shows the thermal diffusivity images for the samples processed with $1,5,9$, and 13 PIP cycles. Thermal diffusivity distribution is generally uniform for these samples, although mean diffusivity value increases with the increase of PIP cycles, due to the increase of the sample density. The average diffusivity is plotted in Fig. 5a as a function of the PIP processing cycle, and in Fig. $5 \mathrm{~b}$ as a function of sample density. Mean thermal diffusivity is linearly proportional to sample density.

\section{$0.4 \mathrm{~mm}^{2} / \mathrm{s}$}

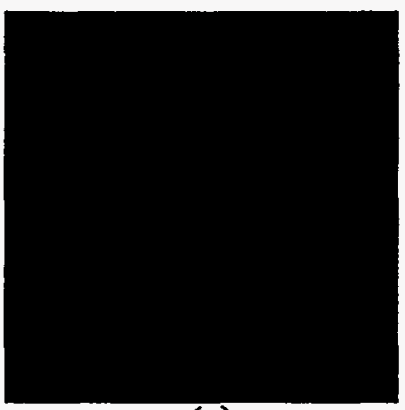

(a)

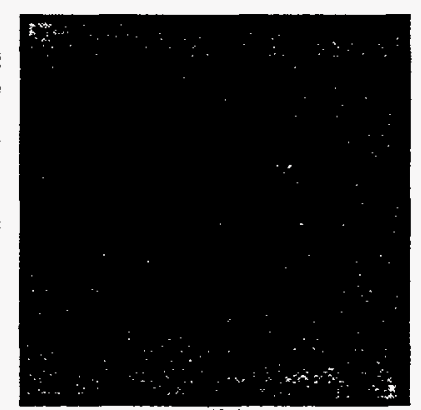

(b)

$1.2 \mathrm{~mm}^{2} / \mathrm{s}$



(c)

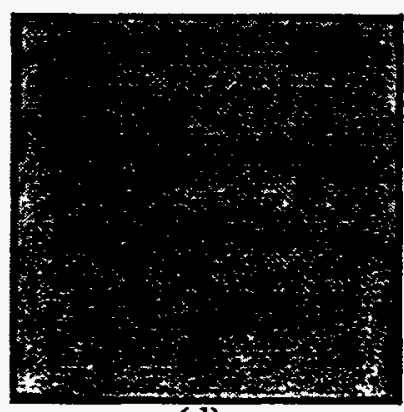

(d)

Fig. 4. Thermal diffusivity images of Dow Corning SYLRAMIC ${ }^{\mathrm{TM}}$ SiC/SiNC composite samples with (a) 1, (b) 5, (c) 9, and (d) 13 PIP processing cycles.

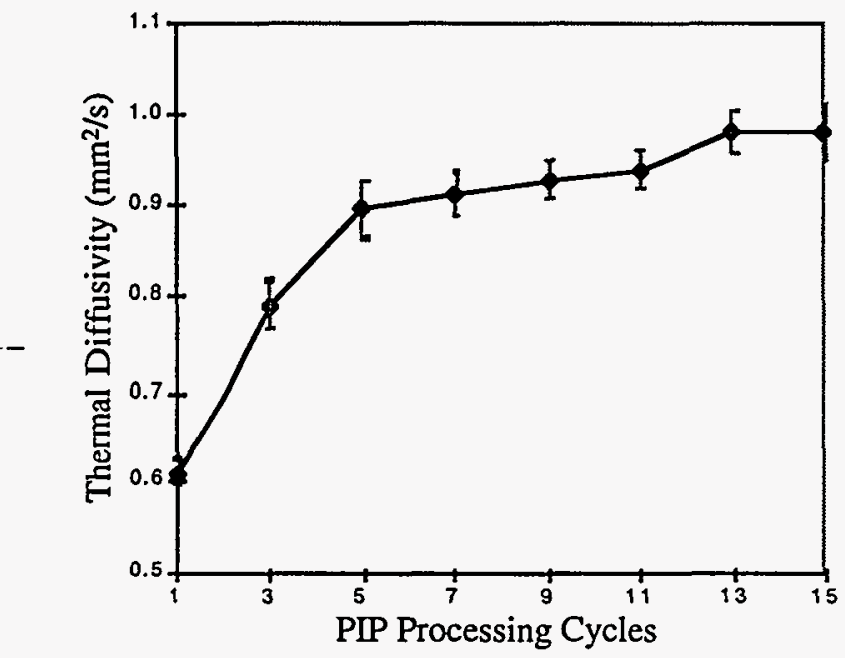

(a)

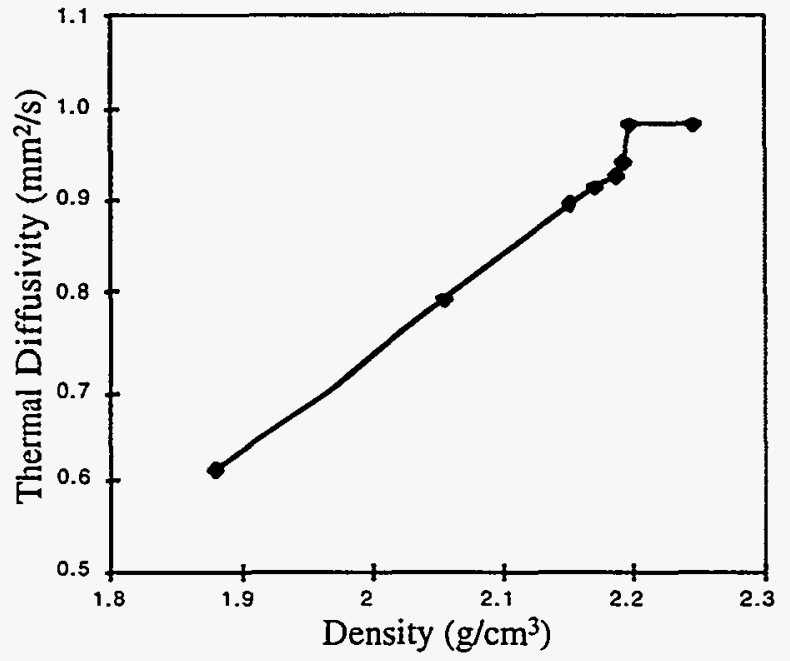

(b)

Fig. 5. Mean thermal diffusivities as a function of (a) PIP processing cycles and (b) density of Dow Corning SYLRAMIC ${ }^{\mathrm{TM}} \mathrm{SiC} / \mathrm{SiNC}$ composite samples. 


\section{DUPONT LANXIDE COMPOSITES SiC/SiC SAMPLES}

Six enhanced $\mathrm{SiC} / \mathrm{SiC}$ and four $\mathrm{SiC} / \mathrm{SiC}$ standard samples (numbered from 1 to 10 ) were produced for this study by DuPont Lanxide Composites, Inc. These samples differed in density, size, and thickness (sample No. 10 was $10.8 \mathrm{~mm}$ thick, samples No. 7 and 9 were $5.6 \mathrm{~mm}$ thick, and the rest were $\approx 2.5 \mathrm{~mm}$ thick). Figure 6 shows typical thermal diffusivity images of these samples. For a thin sample (Fig. 6a), diffusivity distribution is generally uniform, with a small low-diffusivity region (corresponding to low density) at the center due to the processing method used to produce this sample. As the thickness increases (Fig. 6b), diffusivity is higher near the edges of the sample. This phenomenon becomes more evident for the thickest sample, as shown in Fig. 6c. The diffusivity value as a function of the average density for the $\mathrm{SiC} / \mathrm{SiC}$ samples is plotted in Fig. 7. It is seen that thermal diffusivity is approximately a linear function of the measured density. However, the fit of the data is not as good as in Fig. 5(b) due to the density gradient in these samples. The thickest sample (No. 10) falls farthest from the line, presumably due to the incomplete processing in the interior of this thick sample. Therefore, the thermal imaging technique may be used as an indicator of incomplete processing.

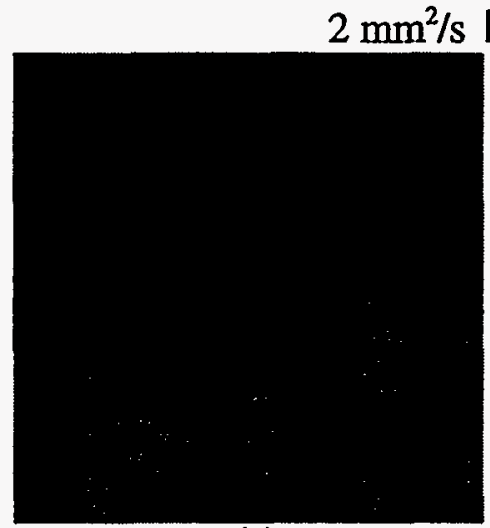

(a)

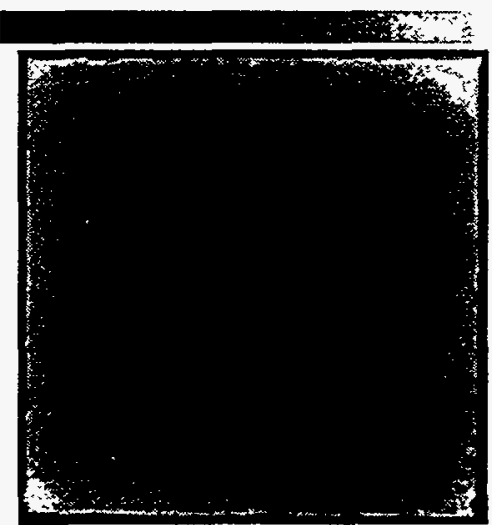

(b)

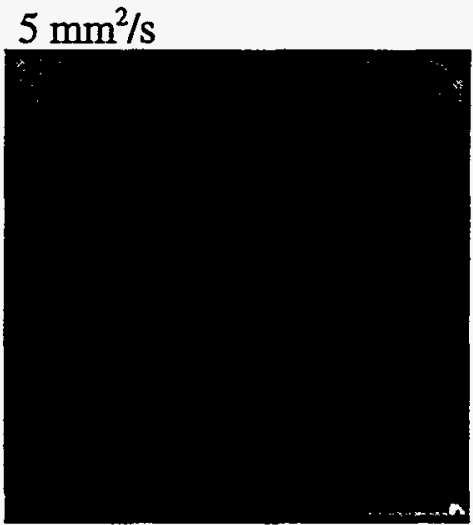

(c)

Fig. 6. Thermal diffusivity images of DuPont Lanxide Composites SiC/SiC samples: (a) No. 6 (2.5 mm thick), (b) No. 9 (5.6 mm thick), and (c) No. 10 (10.8 mm thick).

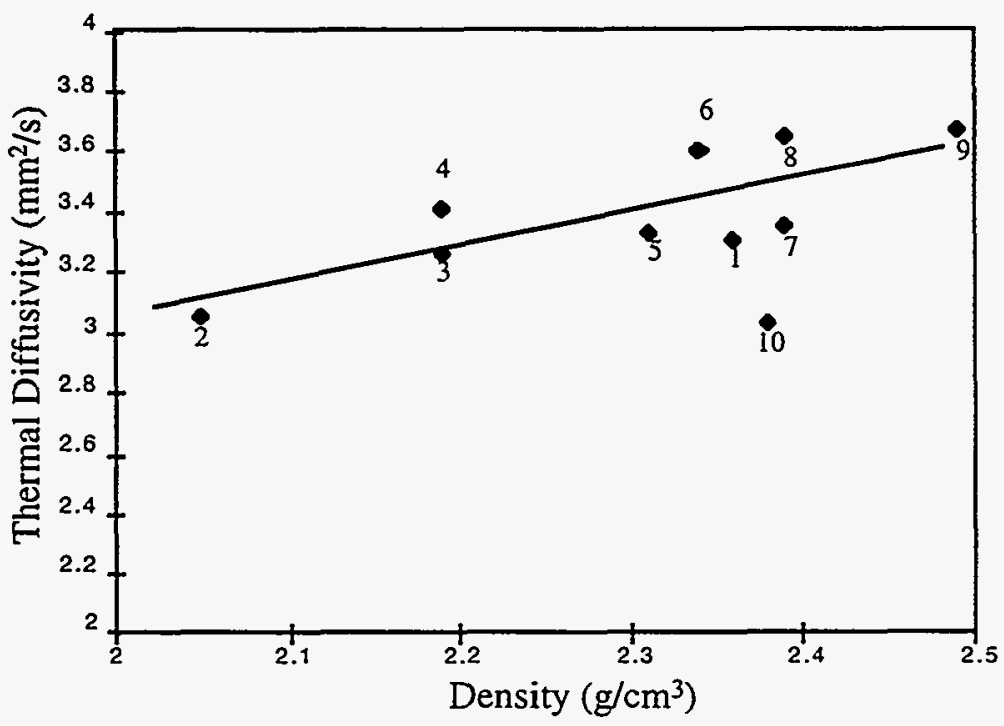

Fig. 7. Mean thermal diffusivities as a function of density for DuPont Lanxide Composites $\mathrm{SiC} / \mathrm{SiC}$ samples. 


\section{CONCLUSIONS}

An infrared thermal imaging system has been developed to measure thermal diffusivity distribution in CFCC materials. The system provides accurate measurements of thermal diffusivity values for standard samples. It was found that thermal diffusivity was linearly proportional to composite density for the SYLRAMIC ${ }^{\mathrm{TM}}$ SiC/SiNC composite samples from Dow Corning and for the $\mathrm{SiC} / \mathrm{SiC}$ and enhanced $\mathrm{SiC} / \mathrm{SiC}$ samples from DuPont Lanxide Composites. Measured thermal diffusivity images indicated variations in sample density (or porosity) that are related to the material processing methods. Therefore, this thermal imaging method may be used for reliable characterization of CFCC materials.

\section{ACKNOWLEDGMENTS}

This work was funded jointly by Dow Corning and the U.S. Department of Energy, Energy Efficiency and Renewable Energy, Office of Industrial Technologies, under Contract W-31-109ENG-88 and Cooperative Agreement Nos. DE-FC02-92CE40993 and DE-FC02-92CE40999.

\section{REFERENCES}

Parker, W. J., Jenkins, R. J., Butler, C. P., and Abbott, G. L., Flash method of determining thermal diffusivity, heat capacity, and thermal conductivity, J. Appl. Phys., 32:1679-1684, 1961.

Stuckey, J., Sun, J. G., and Ellingson, W. A., Rapid infrared characterization of thermal diffusivity in continuous fiber ceramic composite components, presented at 8th Int. Symp. on Nondestructive Characterization of Materials, Boulder, CO, June 15-20, 1997. 